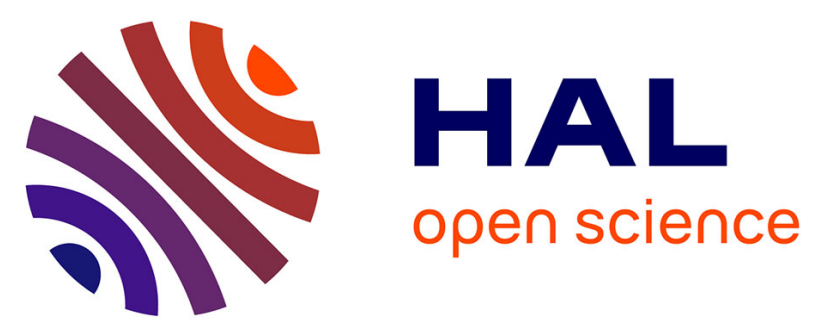

\title{
Economic issues involved in integrating genomic testing into clinical care: the case of genomic testing to guide decision-making about chemotherapy for breast cancer patients
}

Patricia Marino, Carole Siani, François Bertucci, Henri Roche, Anne-Laure

\author{
Martin, Patrice Viens, Valérie Seror
}

\section{To cite this version:}

Patricia Marino, Carole Siani, François Bertucci, Henri Roche, Anne-Laure Martin, et al.. Economic issues involved in integrating genomic testing into clinical care: the case of genomic testing to guide decision-making about chemotherapy for breast cancer patients. Breast Cancer Research and Treatment, 2010, 129 (2), pp.401-409. 10.1007/s10549-010-1242-z . hal-00615386

\author{
HAL Id: hal-00615386 \\ https://hal.science/hal-00615386
}

Submitted on 19 Aug 2011

HAL is a multi-disciplinary open access archive for the deposit and dissemination of scientific research documents, whether they are published or not. The documents may come from teaching and research institutions in France or abroad, or from public or private research centers.
L'archive ouverte pluridisciplinaire $\mathbf{H A L}$, est destinée au dépôt et à la diffusion de documents scientifiques de niveau recherche, publiés ou non, émanant des établissements d'enseignement et de recherche français ou étrangers, des laboratoires publics ou privés. 
Economic issues involved in integrating genomic testing into clinical care:

the case of genomic testing to guide decision-making about chemotherapy

\title{
for breast cancer patients
}

\author{
Patricia MARINO ${ }^{1,2,3}$, Carole SIANI ${ }^{4}$, François BERTUCCI ${ }^{2,3,5}$, Henri ROCHE ${ }^{6}$,
} Anne-Laure MARTIN ${ }^{7}$, PatriceVIENS $^{2,3,5}$, Valérie SEROR ${ }^{1,2}$

1 Inserm, UMR 912 "Economic \& Social Sciences, Health Systems \& Societies”, IRD, F-13000, Marseilles, France;

2 Université Aix-Marseille, F-13000 Marseilles, France;

3 Institut Paoli-Calmettes, F-13000 Marseilles, France;

4 ERIC EA 3083, University of Lyon (University Claude Bernard Lyon 1), F-69622 Lyon, France ;

5 Centre de Recherche en Cancérologie de Marseille, Département d’Oncologie Moléculaire,

InsermUMR891; IFR137, F-13000 Marseille, France ;

6 Institut Claudius Régaud, F-31000 Toulouse, France ;

7 Fédération Nationale des Centres de Lutte Contre le Cancer, F-75000,Paris, France ;

Corresponding author : Patricia MARINO

Inserm UMR 912, Institut Paoli-Calmettes

232, Bd de Sainte Marguerite, 13273 Marseilles Cedex 9 (FRANCE)

Phone: (33) 491223502 ; Fax: (33) 491223504 ;

E-mail: patricia.marino@inserm.fr 


\begin{abstract}
Purpose: The use of taxanes to treat node-positive $(\mathrm{N}+)$ breast cancer patients is associated with heterogeneous benefits as well as with morbidity and financial costs. This study aimed to assess the economic impact of using gene-expression profiling to guide decision-making about chemotherapy, and to discuss the coverage/reimbursement issues involved.
\end{abstract}

Methods: Retrospective data on 246 patients included in a randomized trial (PACS01) were analyzed. Tumours were genotyped using DNA microarrays (189-gene signature), and patients were classified depending on whether or not they were likely to benefit from chemotherapy regimens without taxanes. Standard anthracyclines plus taxane chemotherapy (strategy AT) was compared with the innovative strategy based on genomic testing (GEN). Statistical analyses involved bootstrap methods and sensitivity analyses.

Results: The AT and GEN strategies yielded similar 5-year metastasis-free survival rates. In comparison with AT, GEN was cost-effective when genomic testing costs were less than 2,090€. With genomic testing costs higher than 2,919 euros, AT was cost-effective. Considering a $30 \%$ decrease in the price of docetaxel (the patent rights being about to expire), GEN was cost-effective if the cost of genomic testing was in the $0 €-1,139 €$ range; whereas AT was cost-effective if genomic testing costs were higher than1,891 euros.

Conclusions: The use of gene-expression profiling to guide decision-making about chemotherapy for $\mathrm{N}+$ breast cancer patients is potentially cost-effective. Since genomic testing and the drugs targeted in these tests yield greater well-being than the sum of those resulting from separate use, questions arise about how to deal with extra-well being in decision-making about coverage/reimbursement.

Key Words: cost-effectiveness, breast cancer, genomic testing, adjuvant chemotherapy 


\section{Introduction}

During the last few years, pharmacogenomic research has hold great promises for optimizing the clinical management of cancer patients. Although the pace of development of genomic tests is slower than it was expected to be a few years ago and only a few genomic tests have been marketed so far, issues about insurance coverage and reimbursement have been recently discussed in the context of increasing concern about healthcare costs $[1,2]$.

The need for cost-effectiveness analyses has been stressed by many authors [3,4] since these studies provide third-party payers (private and public health insurance systems) with evidence-based estimates of economic impact on which to base decision-making about coverage/reimbursement $[5,6]$. However, genomic testing of drug response raises specific questions relating to coverage/reimbursement. Since genomic testing and the drugs targeted in these tests should yield greater patients' well-being (due to increased effectiveness and/or fewer side-effects) than the sum of those resulting from separate use, questions arise as to how extra well-being should be assessed and handled in coverage/reimbursement decisionmaking processes. While some authors have pointed out the complementarity existing between genomic testing and the drugs targeted in the context of regulatory approval $[1,7]$, complementarity has not yet been discussed to our knowledge in the context of coverage/reimbursement decisions.

In the field of breast cancer, several studies showed that gene-expression profiling could provide a useful tool for defining tumor subtypes and predicting patients' responses to treatment $[8,9,10]$. Breast cancer is the most common female cancer occurring in industrialized countries, and is still the main cause of cancer-related death among European women [11]. The ability of adjuvant chemotherapy to improve the prognosis of breast cancer and prolong survival has been clearly established [12], and anthracycline-based chemotherapy 
has been the standard adjuvant treatment for breast cancer patients during the last decade. More recently, taxanes (docetaxel and paclitaxel) were introduced into the therapeutic sequence in the case of axillary lymph node-positive $(\mathrm{N}+)$ patients, in addition to regimens based on anthracylines. The majority of $\mathrm{N}+$ patients in France are currently undergoing regimens based on both anthracyclines and taxanes [13]. However, the limited benefit of taxanes in first line chemotherapy [14-18] suggest that many patients probably do not benefit from the adjunction of taxanes [19]. In this context, genomic testing might improve the effectiveness of treatments by determining which patients are likely to benefit most from them, thus avoiding unnecessary therapy and ensuring more cost-effective care [1,20-22].

To investigate these issues, a cost-effectiveness analysis was conducted in which the impact of tumour gene expression profiling was assessed in patients with early $\mathrm{N}+$ breast cancer treated with adjuvant chemotherapy [23,24]. More specifically, the aim of the study was to assess the cost-effectiveness of genomic testing used to identify whether or not $\mathrm{N}+$ breast cancer patients are likely to benefit from a regimen based on anthracyclines alone, i.e. without the adjunction of taxanes. While an ongoing prospective multicentre study (involving three French cancer centers) is focusing on the clinical benefits associated with routine use of gene expression profiling, the present study is based on the currently available retrospective data. This study presents findings on the expected impact of gene expression profiling in terms of both health outcomes and costs of care, and discusses some issues relating to the coverage/reimbursement of genomic testing.

\section{Material and methods}

\section{The data set}

The present cost-effectiveness analysis was performed using on data from the PACS 01 randomized clinical trial [16] carried out by a network of French national cancer centers 
(FNCLCC). In this trial, anthracyline-based chemotherapy (6 cycles of FEC 100) was compared with a combined anthracycline and taxane regimen (3 FEC 100 followed by 3 cycles of docetaxel) in the adjuvant setting in $1999 \mathrm{~N}+$ breast cancer patients. In addition to the clinical data, individual economic data on the patients' hospital care (surgery, chemotherapy and other drugs, laboratory investigations, length of hospital stay, etc;) were available [25].

Tumour genotyping was performed (by Ipsogen, Marseilles, France, http://www.ipsogen.com/) using DNA microarrays from frozen samples collected from 246 patients enrolled in the PACS 01 clinical trial. Among these 246 patients, 128 received a chemotherapy regimen based on anthracylines alone and 118 received a combined anthracyline plus taxane regimen. We recently described a 189-gene expression signature predictive of metastatic relapse after adjuvant anthracycline-based chemotherapy without taxane [24]. This signature was identified in a learning set of 323 patients and subsequently validated in an independent set of 175 patients. Based on this signature, the 246 patients were retrospectively categorized into a good prognosis group (patients likely to benefit from a regimen based on anthracyclines alone) and a poor prognosis group (patients unlikely to benefit from a regimen without taxane). In all, 197 out of the 246 patients were identified as having a good prognosis (105 of the patients in this group received an anthracycline-based chemotherapy and 92 received an anthracycline plus taxane regimen), and 49 were identified as having a poor prognosis (anthracycline-based chemotherapy and anthracycline plus taxane chemotherapy administered to 23 and 26 patients, respectively).

\section{Specification of strategies}

In the present cost-effectiveness analysis, the current standard treatment strategy for $\mathrm{N}+$ breast cancer patients [16] was compared with the innovative strategy involving gene expression 
profiling to guide decision-making about chemotherapy (Figure 1). More specifically, the following strategies were compared:

1. The AT strategy: all patients received a regimen of 3 cycles of anthracyclines followed by three cycles of docetaxel ( 3 FEC $100+3$ docetaxel), which is the standard treatment for N+ patients in France [16].

2. The GEN strategy: all the patients' tumors were genotyped, and the chemotherapy received by patients depended on the results of the gene-expression profiling: 6 cycles of anthracycline-based chemotherapy (FEC100) in good prognosis patients, and anthracyline plus taxane chemotherapy ( 3 FEC $100+3$ docetaxel) in poor prognosis patients.

Since some patients were included in both AT and GEN strategies, comparisons between strategies in terms of effectiveness and costs required specific statistical methods: these are described in the "Statistical Analysis" Section.

\section{Effectiveness of strategies}

The endpoint adopted to assess the effectiveness of these strategies was metastasis-free survival (MFS), as this was the clinical outcome used to identify the gene expression patterns correlated with patients' prognosis. MFS was calculated from the date of diagnosis up to the date of first distant metastasis. Patients who did not have any metastatic relapse were censored. Survival rates and mean survival times were calculated using the Kaplan-Meier method. The variance estimator of the survival times was calculated using bootstrap methods, since no simple expression for this parameter is available. Bootstrap tests were also conducted to determine the equality of mean survival times (for further details, see the "Statistical analysis" Section).

\section{Treatment Costs}


The costs included in the analysis were from the healthcare provider perspective, taking only medical costs into account. As with the effectiveness data, the cost data were obtained on the 246 patients included in the PACS 01 trial [25]. The cost analysis was performed using the micro-costing method, which consisted in measuring resource utilization in physical quantities, combined with a monetary valuation using unit cost data [6]. Physical quantities involved in medical resource utilization were collected prospectively alongside the PACS 01 trial.

The following resource items were collected for calculating costs:

Hospital stays: inpatient stays (number of days) and day clinic visits (number of visits)

Pharmacy: quantities of drugs administered (chemotherapy, antibiotics, Filgrastim G-CSF, anti-emetics, etc.)

Laboratory: the tests and medical investigations specified in the clinical protocol (including pre-treatment tests).

Surgical procedure: mastectomy or breast conserving surgery (lumpectomy).

Monetary values expressed in euros $(€)$ were attributed to all physical quantities consumed (based on the current rate of exchange, $1 €$ is worth about 1.30US\$). Because of the wellknown differences existing between hospital charges and real costs [26], especially in the context of a publicly funded health care system such as the French one, hospital charges were not used to assess the costs associated with hospitalization. Instead of hospital charges, "real cost" per diem of hospitalizations and outpatient visits were used, based on the detailed data on annual expenditures that were routinely collected at a French cancer center's analytic accounting system (Institut Paoli-Calmettes). These costs included that of the staff involved, depreciation of equipment (using a depreciation rate of 20\%), consumable supplies, and food costs. A $20 \%$ overhead rate was added to these hospital costs to account for the administrative resources used [6]. Drug prices were the purchase prices negotiated at national level by the 
Federation of French Cancer Hospitals. Costs of laboratory tests, diagnostic tests and surgical acts were based on the tariffs applied by the French national health insurance system.

Since the clinical trial involved collecting economic data from randomization in the PACS 01 trial up to the end of chemotherapy, the total costs of the treatments were calculated only during this period of time. This limitation can be partly justified by the fact that the posttreatment follow-up and laboratory tests conducted after completion of the treatment were likely to be the same, regardless of which of the two treatment strategies was used.

\section{Cost-effectiveness}

In most cost-effectiveness analyses, the results of comparisons between strategies of care are generally expressed in terms of incremental cost-effectiveness ratios (ICER), which give the additional cost required to reach one additional unit of effectiveness. However, as genomic profiling was designed to avoid over-treatment (adding taxanes) without reducing the effectiveness of chemotherapy [24], the cost-effectiveness analysis could be reduced to a costminimization analysis once the validity of the hypothesis that the effectiveness of both strategies was similar had been confirmed.

\section{Statistical analysis}

Since some patients were included in both the AT and GEN strategies (patients having received anthracycline- and taxane-containing regimens and retrospectively identified as having a poor prognosis based on the results of gene-expression profiling), correlations between the data make the standard statistical methods not appropriate. To deal with this problem, bootstrap methods were used which consist in resampling and simultaneously replacing variables (costs, survival times, occurrence of events, and strategy) to preserve the correlations between them. This procedure was repeated a large number of times $(10,000$ times in this case). Based on the variance of the survival differences and the variance of the 
costs differences thus obtained, bootstrap tests were carried out to determine the equality of mean survival times and the equality of average costs. Confidence intervals were calculated on the difference between the mean costs of the two strategies compared.

\section{Sensitivity analysis}

Sensitivity analyses were conducted by varying some key parameters in order to assess the robustness of the cost findings. Given the high likelihood that genomic testing would strongly affect the cost of the GEN strategy, the first key parameter tested was the cost of genomic testing (including preservation and transportation of the samples, RNA extraction, as well as the price of genomic testing, which has not yet been set). The second key parameter in the assessment of the AT and GEN strategies was the purchase price of docetaxel, since this drug will soon become available as a generic drug (patent rights expired in 2010 in the US and most European countries), and will therefore cost less than its brand name counterpart. These parameters were varied simultaneously (cost of genomic testing was taken to be in the $0 €$ $5,000 €$ range, and the price of docetaxel was taken to decrease by $-10 \%$ to $-60 \%$ ), and the difference between the costs of the two strategies (including 95\% CI) was calculated.

\section{Results}

The clinical characteristics of the 246 patients included in this analysis are presented in Table 1. All the patients were between 29 and 64 years of age and they all had histologically confirmed axillary lymph node involvement without any metastases. Among these 246 patients, 128 received an anthracycline-based chemotherapy without taxane, and 118 received combined anthracycline/taxane chemotherapy. The regimen involving anthracyline consisted of fluorouracil $500 \mathrm{mg} / \mathrm{m}^{2}$, epirubicin $100 \mathrm{mg} / \mathrm{m}^{2}$ and cyclophosphamide $500 \mathrm{mg} / \mathrm{m}^{2}$. The chemotherapy regimen involving taxane consisted of three cycles of the same FEC regimen, 
followed by three cycles of docetaxel $100 \mathrm{mg} / \mathrm{m}^{2}$. The patients' clinical characteristics were well balanced between treatment groups (anthracycline $v s$ taxane, $\mathrm{p}>0.05$ in all the cases).

Among these 246 patients, genomic testing led to identifying 197 patients $(80.1 \%, 95 \% \mathrm{CI}$ : $75.1 \%-85.1 \%)$ as having a good prognosis, while the remaining 49 patients $(19.9 \%, 95 \% \mathrm{CI}$ : $14.9 \%-24.9 \%$ ) were found to have a poor prognosis. Since the clinical PACS 01 trial was not designed to assess the impact of genomic testing on patients' health outcomes, it emerged that $53.3 \%$ of the patients with a good prognosis received a chemotherapy regimen without taxane while $47.7 \%$ received a combined anthracycline/taxane regimen. Conversely, $47.9 \%$ of the patients classified as having a poor prognosis received a taxane-free chemotherapy regimen, while $53.1 \%$ received a combined anthracycline/taxane regimen (Table 2).

\section{Effectiveness of therapeutic strategies}

The survival rates are summarized in Table 2. Effectiveness of strategies was calculated in terms of metastasis-free survival (MFS) during a median follow-up time of 60 months. The 5year MFS was $81.4 \%$ in the case of the AT strategy and $83.4 \%$ in that of the GEN strategy $(\mathrm{p}=0.34)$

Patients in the good prognosis group had similar survival times regardless of the treatment undergone (5-year MFS was $87.0 \%$ and $84.9 \%$, depending on whether or not the chemotherapy regimen included taxanes), which suggests that these patients did not benefit from the adjunction of taxanes. In the poor prognosis group, the 5-year MFS was higher among the patients who had received taxane than among those who had not $(69.2 \%$ vs $60.9 \%)$, although this difference was not statistically significant because of the small numbers involved $(\mathrm{p}=0.58)$.

\section{Treatments costs and cost-minimization analysis}


Based on the measurement of the resources individually consumed by the 246 patients involved in the analysis, the average treatment costs associated with the AT and GEN strategies are presented in Table 3, along with the proportions of the costs attributable to the various cost categories. Note that the treatment cost values given in Table 3 include docetaxel priced as a brand name drug.

Taking only the costs incurred during the treatment period, the mean cost per patient in the case of the AT strategy was $12,688 €(95 \% \mathrm{CI}:[12,329 ; 13,047])$, where the purchase cost of taxanes amounted to $31.9 \%$ of the total cost. In the case of the GEN strategy, the mean cost per patient (not including the cost of gene expression profiling) was $10,184 €(95 \% \mathrm{CI}$ : [9,825 ; 10,543]), which is $19.6 \%$ lower than with the AT strategy. With cost savings of 2,504€ per patient (95\%CI: $[-2,999 ;-2,010])$ without any loss of effectiveness, the GEN strategy therefore turned out to be preferable to the standard docetaxel-based AT strategy $(\mathrm{p}<0.001)$.

Since gene expression profiling is currently performed only in clinical trials designed to prospectively assess patients' health outcomes, it is not covered by the French health insurance system and has therefore not been priced. Taking the cost of genomic testing into account yielded the results presented in Figure 2. With genomic testing costs below 2,090€ (including tumour sample preparation, transportation, and testing), the GEN strategy dominated the AT strategy as it was significantly less costly; whereas taking the costs of genomic testing to amount to more than 2,919€ made the strategy AT cost-effective. When the genomic testing costs ranged between these two values, the total cost of AT and GEN strategies was similar, and the two strategies were therefore equivalent.

Since all the results presented above were based on docetaxel priced as a brand name drug, and since taxanes accounted for $31.9 \%$ and $7.3 \%$ of the mean cost of strategies AT and GEN, respectively, a sensitivity analysis was carried out on the cost of genomic testing and that of 
docetaxel (Figure 2). Since generic drugs usually cost about 30\%-40\% less than their brand name counterparts, a 30\% decrease in the price of docetaxel was applied. In this case, the GEN strategy dominated the AT strategy when the cost of genomic testing was in the $0 €-$ $1,139 €$ range. Conversely, the AT strategy was cost-effective when the cost of genomic testing was taken to be greater than $1,891 €$. The two strategies were found to be equivalent when the cost of genomic testing was taken to range between $1,139 €$ and $1,891 €$.

\section{Discussion}

Gene expression profiling could help to refine medical decision-making, but some questions about its economic impact need to be addressed before it can be used in routine clinical settings $[27,28]$. It is thus necessary to determine whether the use of genomic testing yields clinical benefits that justify the additional cost of testing all patients [21,29]. Although the cost of genomic testing is likely to be substantial, targeting treatments more selectively to those patients who are likely to benefit most might prevent therapeutic escalation and the corresponding costs.

The present assessment of the potential impact of gene expression profiling on the cost of treatment and the survival of $\mathrm{N}+$ breast cancer patients shows that the therapeutic strategy involving genomic testing is potentially cost-effective, depending on the cost of genomic testing. With costs lower than $2,090 €$ at the current drug prices (or less than $1,139 €$ when the price of docetaxel was assumed to drop by $30 \%$ once it has become a generic drug), treatment decisions based on gene expression profiling were found to be equally effective but significantly less costly than the strategy involving taxanes administered to all patients. Taking the cost of genomic testing to be in the $2,090 €$ to $2,919 €$ range (or in the $1,139 €$ to $1,891 €$ range if the price of docetaxel decreases by $30 \%$ ), the two strategies were found to have similar costs and effectiveness. It is worth noting that these costs (including tumour 
sample preparation and transportation) turned out to be lower than the price of the currently available genomic tests for breast cancer patients ( $\$ 3,460$ for Oncotype $\mathrm{DX}^{\mathrm{TM}}$ [30], for example).

This analysis is subject to a number of limitations. First, the number of patients in our study sample was rather small, especially in the case of the poor prognosis group, in which the patients received an anthracyline plus taxane chemotherapy regimen. Another limitation is the existence of some uncertainty about the predictive value of gene expression profiling, as the clinical findings were based on retrospective data [24]. However, the latter limitation is common to many studies, and no direct evidence has been provided so far that gene expression profiling improves breast cancer patients' outcomes [31].

A few studies have addressed the economic impact of gene expression profiling in the treatment of breast cancer patients. The results of these studies are not directly comparable with ours, however, mainly because of the differences between the therapeutic indications for gene expression profiling $(\mathrm{N}+$ patients in our case, versus $\mathrm{N}$ - patients in previous studies). In the study by Hornberger et al., the cost-utility of using a 21-gene expression signature to reclassify patients initially defined as low- or high-risk patients according to the National Comprehensive Cancer Network $(\mathrm{NCCN})$ clinical guidelines, was calculated as $\$ 31,452$ per QALY gained, and the authors concluded that genomic testing has the potential to increase quality-adjusted survival and save costs [32]. These results were recently confirmed on a larger set of patients [33]. The study by Oestreicher et al. led to similar conclusions and suggested that performing gene expression profiling to identify the high-risk breast cancer patients who are likely to benefit most from adjuvant chemotherapy may yield net cost savings of $\$ 2,882$ per patient [34]. All these studies were based on retrospective data, and their authors pointed out that the evidence about the economic outcomes was not very solid, 
since cost-effectiveness is difficult to assess until the clinical relevance of genomic testing for treatment decision-making purposes is confirmed.

In view of the need expressed for cost-effectiveness analyses to inform decision-making about coverage/reimbursement, it is worth noting that cost-effectiveness findings do not actually solve this issue. Coverage/reimbursement decisions cannot be reduced to a matter of balancing health insurance budgets, since they are liable to affect the development of the newly developing pharmacogenomic sector: low pricing might create a negative incentive for developing new genomic tests, whereas high pricing might favour opportunities for rent seeking that would actually be financed by the health insurance subscribers.

Another issue relating to coverage/reimbursement is that genomic testing and the drug targeted are complementary $[35,36]$, which means that their joint use results in greater wellbeing than the sum of those resulting from separate use. In particular, undergoing genomic testing generates very little if any well-being if the drug targeted is not available. Since higher value is usually attached to greater well-being, the question arises as to how increased wellbeing should be priced. In view of the fact that genomic testing is intended to prevent overtreatment and to reduce the magnitude and/or frequency of side-effects, well-being could be approached by assessing patients' quality of life. Although the issue of the monetary value of quality of life has been addressed by a few authors [37-39], these studies are still in the exploratory stage.

The last point concerns the use of thresholds to classify patients depending on the results of genomic testing. In line with the premises of 'personalized medicine', it seems somewhat contradictory to determine individual gene expression profiles and then express the results in terms of belonging to a group. Greater consistency could be achieved by expressing individual genomic test results in terms of the probability of responding to the drug targeted, 
for example. This would enable physicians and patients to make better informed decisions and inform the payers' decision-making about coverage, since the question would then arise as to how an 'acceptable' probability of responding to drugs should be defined.

\section{Conclusion}

The introduction of new drugs in the adjuvant setting often yields rather low and heterogeneous benefits and generates morbidity and financial costs. The use of genomic tests targeting currently available drugs might therefore provide a useful means of preventing therapeutic escalation and the associated costs. The results of the present study suggest that genotyping breast cancer patients to guide medical decision-making about chemotherapy : restricting the administration of taxanes to those patients who are most likely to benefit from the treatment should decrease the cost of care. Further cost-effectiveness analyses based on prospectively collected data are now required to confirm these preliminary findings. Clinical trials could also provide insights on patients' quality of life and the acceptability of genomic testing to physicians and patients as a means of guiding decision-making about chemotherapy.

\section{Acknowledgements}

This study was supported by a grant from the "Fondation de France". The authors thank Dr. Jessica Blanc for revising the English manuscript. The authors also thank Christian de Peretti for valuable discussions about bootstrap.

\section{References}

1. Davis JC, Furstenthal L, Desai AA, Norris T, Sutaria S, Fleming E, Ma P (2009) The microeconomics of personalized medicine: today's challenge and tomorrow's promise. Nat Rev Drug Discov 8(4):279-286. 
2. Phillips KA, Veenstra DL, Ramsey SD, Van Bebber SL, Sakowski J (2004) Genetic testing and pharmacogenomics: issues for determining the impact to healthcare delivery and costs. Am J Manag Care 10(7):425-432.

3. Houtsma D, Guchelaar HJ, Gelderblom H (2010) Pharmacogenetics in Oncology: A Promising Field. Curr Pharm Des 16(2) 155-163.

4. Vegter S, Boersma C, Rozenbaum M, Wilffert B, Navis G, Postma MJ (2008) Pharmacoeconomic evaluations of pharmacogenetic and genomic screening programmes: a systematic review on content and adherence to guidelines. Pharmacoeconomics 26(7):569-587.

5. Deverka PA (2009) Pharmacogenomics, evidence, and the role of payers. Public Health Genomics 12(3):149-157.

6. Drummond M, O'Brien B, Stoddart G (1997) Methods for the economic evaluation of health care programs. Second Edition. Oxford Medical Publications, Oxford University Press, New York.

7. Evans BJ (2007) Distinguishing product and practice regulation in personalized medicine. Clin Pharmacol Ther 81(2):288-293.

8. van 't Veer LJ, Dai H, van de Vijver MJ, He YD, Hart AA, Mao M, Peterse HL, van der Kooy K, Marton MJ, Witteveen AT et al (2002) Gene expression profiling predicts clinical outcome of breast cancer. Nature 415(6871):530-536.

9. van de Vijver MJ, He YD, van't Veer LJ, Dai H, Hart AA, Voskuil DW, Schreiber GJ, Peterse JL, Roberts C, Marton MJ et al (2002)A gene-expression signature as a predictor of survival in breast cancer. N Engl J Med 347(25):1999-2009.

10. Bertucci F, Finetti P, Cervera N, Maraninchi D, Viens P, Birnbaum D (2006) Gene expression profiling and clinical outcome in breast cancer. Omics 10(4):429-443.

11. Bray F, Sankila R, Ferlay J, Parkin DM (2002) Estimates of cancer incidence and mortality in Europe in 1995. Eur J Cancer 38(1):99-166.

12. Early Breast Cancer Trialists' Cooperative Group (2005) Effects of chemotherapy and hormonal therapy for early breast cancer on recurrence and 15-year survival: an overview of the randomised trials. Lancet 365(9472):1687-1717.

13. Piccart MJ, de Valeriola D, Dal Lago L, de Azambuja E, Demonty G, Lebrun F, Bernard-Marty C, Colozza M, Cufer T (2005) Adjuvant chemotherapy in 2005: standards and beyond. Breast 14(6):439-445.

14. Mamounas EP, Bryant J, Lembersky B, Fehrenbacher L, Sedlacek SM, Fisher B, Wickerham DL, Yothers G, Soran A, Wolmark N (2005) Paclitaxel after doxorubicin 
plus cyclophosphamide as adjuvant chemotherapy for node-positive breast cancer: results from NSABP B-28. J Clin Oncol 23(16):3686-3696.

15. Martin M, Pienkowski T, Mackey J, Pawlicki M, Guastalla JP, Weaver C, Tomiak E, Al-Tweigeri T, Chap L, Juhos E et al. (2005) Adjuvant docetaxel for node-positive breast cancer. N Engl J Med 352(22):2302-2313.

16. Roche H, Fumoleau P, Spielmann M, Canon JL, Delozier T, Serin D, Symann M, Kerbrat P, Soulie P, Eichler F et al. (2006) Sequential adjuvant epirubicin-based and docetaxel chemotherapy for node-positive breast cancer patients: the FNCLCC PACS 01 Trial. J Clin Oncol 24(36):5664-5671.

17. Buzdar AU, Singletary SE, Valero V, Booser DJ, Ibrahim NK, Rahman Z, Theriault RL, Walters R, Rivera E, Smith TL et al (2002) Evaluation of paclitaxel in adjuvant chemotherapy for patients with operable breast cancer: preliminary data of a prospective randomized trial. Clin Cancer Res 8(5):1073-1079.

18. Bria E, Nistico C, Cuppone F, Carlini P, Ciccarese M, Milella M, Natoli G, Terzoli E, Cognetti F, Giannarelli D (2006) Benefit of taxanes as adjuvant chemotherapy for early breast cancer: pooled analysis of 15,500 patients. Cancer 106(11):2337-2344.

19. Campone M, Fumoleau P, Bourbouloux E, Kerbrat P, Roche H (2005) Taxanes in adjuvant breast cancer setting: which standard in Europe? Crit Rev Oncol Hematol 55(3):167-175.

20. Veenstra DL, Higashi MK, Phillips KA (2000) Assessing the cost-effectiveness of pharmacogenomics. AAPS PharmSci 2(3) E29.

21. Flowers CR, Veenstra D (2004) The role of cost-effectiveness analysis in the era of pharmacogenomics. Pharmacoeconomics 22(8):481-493.

22. Guttmacher AE, Collins FS (2002) Genomic medicine--a primer. N Engl J Med 347(19):1512-1520.

23. Bertucci F, Nasser V, Granjeaud S, Eisinger F, Adelaide J, Tagett R, Loriod B, Giaconia A, Benziane A, Devilard E et al (2002) Gene expression profiles of poorprognosis primary breast cancer correlate with survival. Hum Mol Genet 11(8):863872.

24. Bertucci F, Borie N, Roché H, Bachelot T, Le Doussal JM, Macgrognan G, Debono S, Martinec A et al (2010) Gene expression profile predicts outcome after anthracyclinebased adjuvant chemotherapy in early breast cancer. Breast Cancer Res Treat (in press). 
25. Marino P, Siani C, Roche H, Protiere C, Fumoleau P, Spielmann M, Martin AL, Viens P, Le Corroller Soriano AG (2010) Cost-effectiveness of adjuvant docetaxel for nodepositive breast cancer patients: results of the PACS 01 economic study. Ann Oncol (in press).

26. Finkler SA (1982) The distinction between cost and charges. Annals of Internal Medicine 96(1):102-109.

27. Sims AH, Ong KR, Clarke RB, Howell A (2006) High-throughput genomic technology in research and clinical management of breast cancer. Exploiting the potential of gene expression profiling: is it ready for the clinic? Breast Cancer Res $8(5): 214$.

28. Roden DM, Altman RB, Benowitz NL, Flockhart DA, Giacomini KM, Johnson JA, Krauss RM, McLeod HL, Ratain MJ, Relling MV et al (2006) Pharmacogenomics: challenges and opportunities. Ann Intern Med 145(10):749-757.

29. Swen JJ, Huizinga TW, Gelderblom H, de Vries EG, Assendelft WJ, Kirchheiner J, Guchelaar HJ (2007) Translating pharmacogenomics: challenges on the road to the clinic. PLoS Med 4(8) e209.

30. Ross JS, Hatzis C, Symmans WF, Pusztai L, Hortobagyi GN (2008) Commercialized multigene predictors of clinical outcome for breast cancer. Oncologist 13(5):477-493.

31. Lyman GH, Kuderer NM (2006) Gene expression profile assays as predictors of recurrence-free survival in early-stage breast cancer: a metaanalysis. Clin Breast Cancer 7(5):372-379.

32. Hornberger J, Cosler LE, Lyman GH (2005) Economic analysis of targeting chemotherapy using a 21-gene RT-PCR assay in lymph-node-negative, estrogenreceptor-positive, early-stage breast cancer. Am J Manag Care 11(5):313-324.

33. Lyman GH, Cosler LE, Kuderer NM, Hornberger J (2007) Impact of a 21-gene RTPCR assay on treatment decisions in early-stage breast cancer: an economic analysis based on prognostic and predictive validation studies. Cancer 109(6):1011-1018.

34. Oestreicher N, Ramsey SD, Linden HM, McCune JS, van't Veer LJ, Burke W, Veenstra DL (2005) Gene expression profiling and breast cancer care: what are the potential benefits and policy implications? Genet Med 7(6):380-389.

35. Chen MK, Nalebuff B (2006) One-Way Essential Complements. Cowles Foundation Discussion Paper vol. 1588, Yale University.

36. Gabszewicz J, Sonnac N, Wauthy X (2001) On Price Competition with Complementary Goods. Economics Letters 70(3):431-437. 
37. Hirth RA, Chernew ME, Miller E, Fendrick AM, Weissert WG (2000) Willingness to pay for a quality-adjusted life year: in search of a standard. Med Decis Making 20(3):332-342.

38. Pinto-Prades JL, Loomes G, Brey R (2009) Trying to estimate a monetary value for the QALY. J Health Econ 28(3):553-562.

39. Mason H, Jones-Lee M, Donaldson C (2009) Modelling the monetary value of a QALY: a new approach based on UK data. Health Econ 18(8):933-950. 


\section{Tables and figures}

Table 1. Clinical characteristics of patients included in the cost-effectiveness analysis.

Table 2. 5-year MFS of good and poor prognosis patients, according to the treatment received.

Table 3. Treatment costs associated with strategies AT and GEN.

Figure 1. Decision tree: the two strategies compared

Figure 2. Sensitivity analysis 


\section{Table 1. Clinical characteristics of patients included in the cost-effectiveness analysis}

\begin{tabular}{lccc}
\hline & All patients & $\begin{array}{c}\text { Patients receiving } \\
\text { 6 FEC 100 } \\
(\mathrm{n}=128)\end{array}$ & $\begin{array}{c}\text { Patients receiving } \\
\text { 3 FEC 100 + 3 Docetaxel }{ }^{2} \\
(\mathrm{n}=118)\end{array}$ \\
\hline $\begin{array}{c}\text { Age (years) } \\
\text { mean } \pm \text { sd } \\
\text { range }\end{array}$ & $\begin{array}{c}50 \pm 8 \\
29-65\end{array}$ & $\begin{array}{c}50 \pm 7.6 \\
31-65\end{array}$ & $\begin{array}{c}50 \pm 8.3 \\
29-65\end{array}$ \\
\hline $\begin{array}{l}\text { Hormonal status } \\
\text { premenauposal } \\
\text { menauposal }\end{array}$ & $145(59.4 \%)$ & $77(60.6 \%)$ & $68(58.1 \%)$ \\
& $99(40.6 \%)$ & $50(39.4 \%)$ & $49(41.9 \%)$ \\
\hline $\begin{array}{l}\text { ER status } \\
\text { negative } \\
\text { positive }\end{array}$ & $56(22.8 \%)$ & $33(25.8 \%)$ & $23(19.5 \%)$ \\
\hline $\begin{array}{l}\text { PR status } \\
\text { negative } \\
\text { positive }\end{array}$ & $190(77.2 \%)$ & $95(74.2 \%)$ & $95(80.5 \%)$ \\
& $162(33.3 \%)$ & $41(32.0 \%)$ & $41(34.7 \%)$ \\
\hline
\end{tabular}

$\begin{array}{cccc}\text { SBR grade } & & & \\ \text { SBR I } & 41(16.9 \%) & 20(15.9 \%) & 21(17.9 \%) \\ \text { SBR II } & 91(37.4 \%) & 46(36.5 \%) & 46(39.0 \%) \\ \text { SBR III } & 105(43.2 \%) & 58(46.0 \%) & 47(39.8 \%) \\ \text { non gradable } & 6(2.5 \%) & 2(1.6 \%) & 4(3.4 \%)\end{array}$

\begin{tabular}{cccc}
\hline Number of involved lymph nodes & & \\
mean \pm sd & $3.95 \pm 4.0$ & $3.97 \pm 3.9$ & $3.80 \pm 3.9$ \\
range & $1-23$ & $1-22$ & $1-23$ \\
$<=3$ & $151(61.6 \%)$ & $80(62.5 \%)$ & $71(61.0 \%)$ \\
$>3$ & $94(38.4 \%)$ & $48(37.5 \%)$ & $46(39.0 \%)$
\end{tabular}

\begin{tabular}{llll}
\hline Genomic testing & & & \\
Good prognosis & $197(80 \%)$ & $105(82 \%)$ & $92(78 \%)$ \\
Poor prognosis & $49(20 \%)$ & $23(18 \%)$ & $26(22 \%)$ \\
\hline
\end{tabular}

\footnotetext{
${ }^{1} 6$ cycles of fluorouracil $500 \mathrm{mg} / \mathrm{m}^{2}$, epirubicin $100 \mathrm{mg} / \mathrm{m}^{2}$ and cyclophosphamide $500 \mathrm{mg} / \mathrm{m}^{2}$.

${ }^{2} 3$ cycles of fluorouracil $500 \mathrm{mg} / \mathrm{m}^{2}$, epirubicin $100 \mathrm{mg} / \mathrm{m}^{2}$ and cyclophosphamide $500 \mathrm{mg} / \mathrm{m}^{2}$ followed by 3 cycles of Docetaxel $100 \mathrm{mg} / \mathrm{m}^{2}$,

ER: oestrogen receptor ; PR: progesterone receptor; SBR: Scarff Bloom Richardson
} 
Table 2. 5-year MFS* of good and poor prognosis patients, according to the treatment received.

\begin{tabular}{|c|c|c|c|}
\hline \multirow[b]{2}{*}{ All patients } & \multirow[b]{2}{*}{$n=246$} & \multicolumn{2}{|c|}{ Receiving } \\
\hline & & $\begin{array}{c}6 \text { FEC } 100^{1} \\
(n=128) \\
\end{array}$ & $\begin{array}{c}\text { 3FEC100 + 3Docetaxel }{ }^{2} \\
(n=118)\end{array}$ \\
\hline \multicolumn{2}{|c|}{ Good prognosis $(n=197)$} & $n=105$ & $\mathrm{n}=92$ \\
\hline 5-year MFS & $\begin{array}{l}\% \text { survival } \\
95 \% \text { IC }\end{array}$ & $\begin{array}{c}87.0 \% \\
{[78.6 \% ; 92.3 \%]}\end{array}$ & $\begin{array}{c}84.9 \% \\
{[75.3 \% ; 91.0 \%]}\end{array}$ \\
\hline \multicolumn{2}{|c|}{ Poor prognosis $(n=49)$} & $n=23$ & $n=26$ \\
\hline 5-year MFS & $\begin{array}{l}\% \text { survival }(95 \% \text { IC }) \\
95 \% \text { IC }\end{array}$ & $\begin{array}{c}60.9 \% \\
{[38.3 \% ; 77.4 \%]}\end{array}$ & $\begin{array}{c}69.2 \% \\
{[47.8 \% ; 83.3 \%]}\end{array}$ \\
\hline
\end{tabular}

\footnotetext{
* MFS: metastasis-free survival

${ }^{1} 6$ cycles of fluorouracil $500 \mathrm{mg} / \mathrm{m}^{2}$, epirubicin $100 \mathrm{mg} / \mathrm{m}^{2}$ and cyclophosphamide $500 \mathrm{mg} / \mathrm{m}^{2}$.

${ }^{2} 6$ cycles of fluorouracil $500 \mathrm{mg} / \mathrm{m}^{2}$, epirubicin $100 \mathrm{mg} / \mathrm{m}^{2}$ and cyclophosphamide $500 \mathrm{mg} / \mathrm{m}^{2}$

followed by 3 cycles of Docetaxel $100 \mathrm{mg} / \mathrm{m}^{2}$,
}

Table 3. Treatment costs associated with strategies AT and GEN *

\begin{tabular}{|c|c|c|c|c|}
\hline \multirow{3}{*}{ Strategies } & \multirow{2}{*}{\multicolumn{2}{|c|}{$\begin{array}{c}\text { Strategy AT } \\
3 \text { FEC } 100+3 \text { Docetaxel }(n=118)\end{array}$}} & \multirow{2}{*}{\multicolumn{2}{|c|}{$\begin{array}{l}\text { Strategy GEN } \\
\text { According to genomic profile }(n=131)\end{array}$}} \\
\hline & & & & \\
\hline & average cost & $\%$ total cost & average cost & $\%$ total cost \\
\hline \multicolumn{5}{|l|}{ 1. Therapeutic sequence only } \\
\hline Surgery & $3573 €$ & $28 \%$ & $3619 €$ & $35,5 \%$ \\
\hline $\begin{array}{c}\text { Hospitalisation } \\
\text { (including toxicity) }\end{array}$ & $1160 €$ & $9,1 \%$ & $1119 €$ & $11,0 \%$ \\
\hline Drugs & $5417 €$ & $42,7 \%$ & $2896 €$ & $28,4 \%$ \\
\hline Chemotherapy & $5015 €$ & $39,5 \%$ & $2346 €$ & $23,0 \%$ \\
\hline including Docetaxel & $4081 €$ & $32,2 \%$ & $750 €$ & $7,4 \%$ \\
\hline Other & $402 €$ & $3,2 \%$ & $550 €$ & $5,4 \%$ \\
\hline Laboratory & $2538 €$ & $20,0 \%$ & $2549 €$ & $25,0 \%$ \\
\hline Total cost & $12688 €$ & & $10183 €$ & \\
\hline $95 \%$ confidence intervall & {$[12329 ; 1304$} & & {$[9825 ; 10543]$} & \\
\hline
\end{tabular}

\footnotetext{
*ost of genomic testing not included in the total cost

Note1: $1 €=1.3$ US $\$$

Note2: the treatment cost values include docetaxel priced ad a brand name drug.
}

Fig1. Decision tree: the two strategies compared 


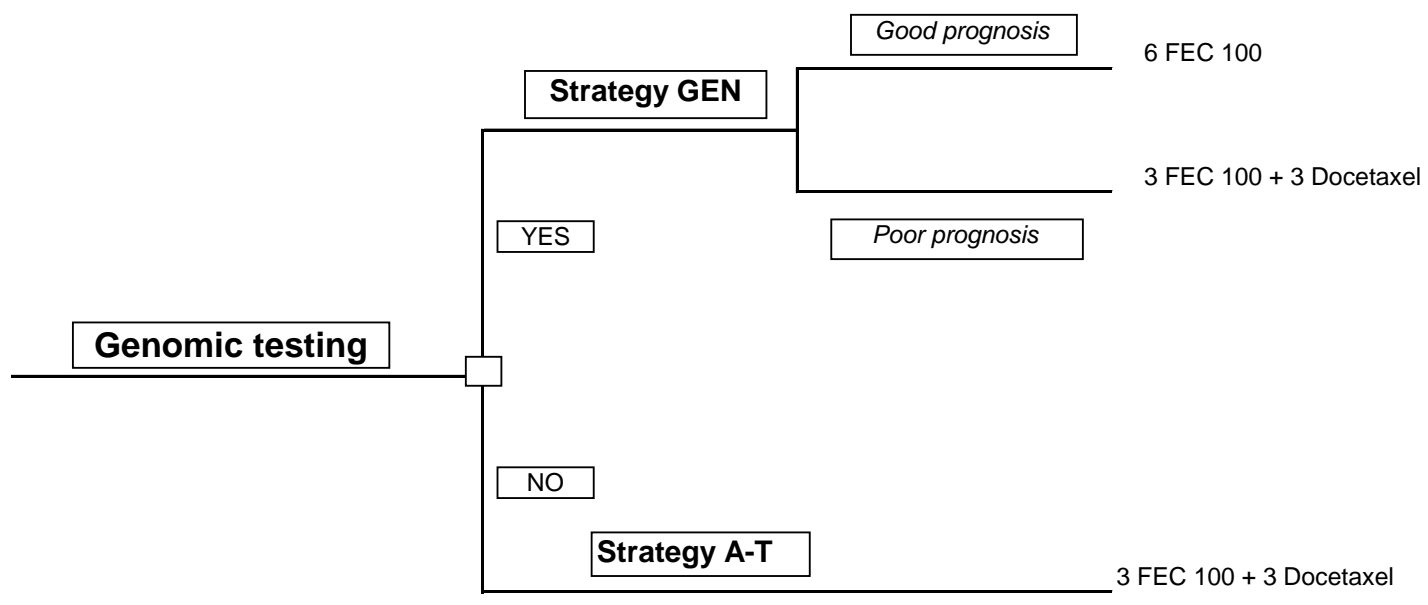

Figure 2. Sensitivity analysis 


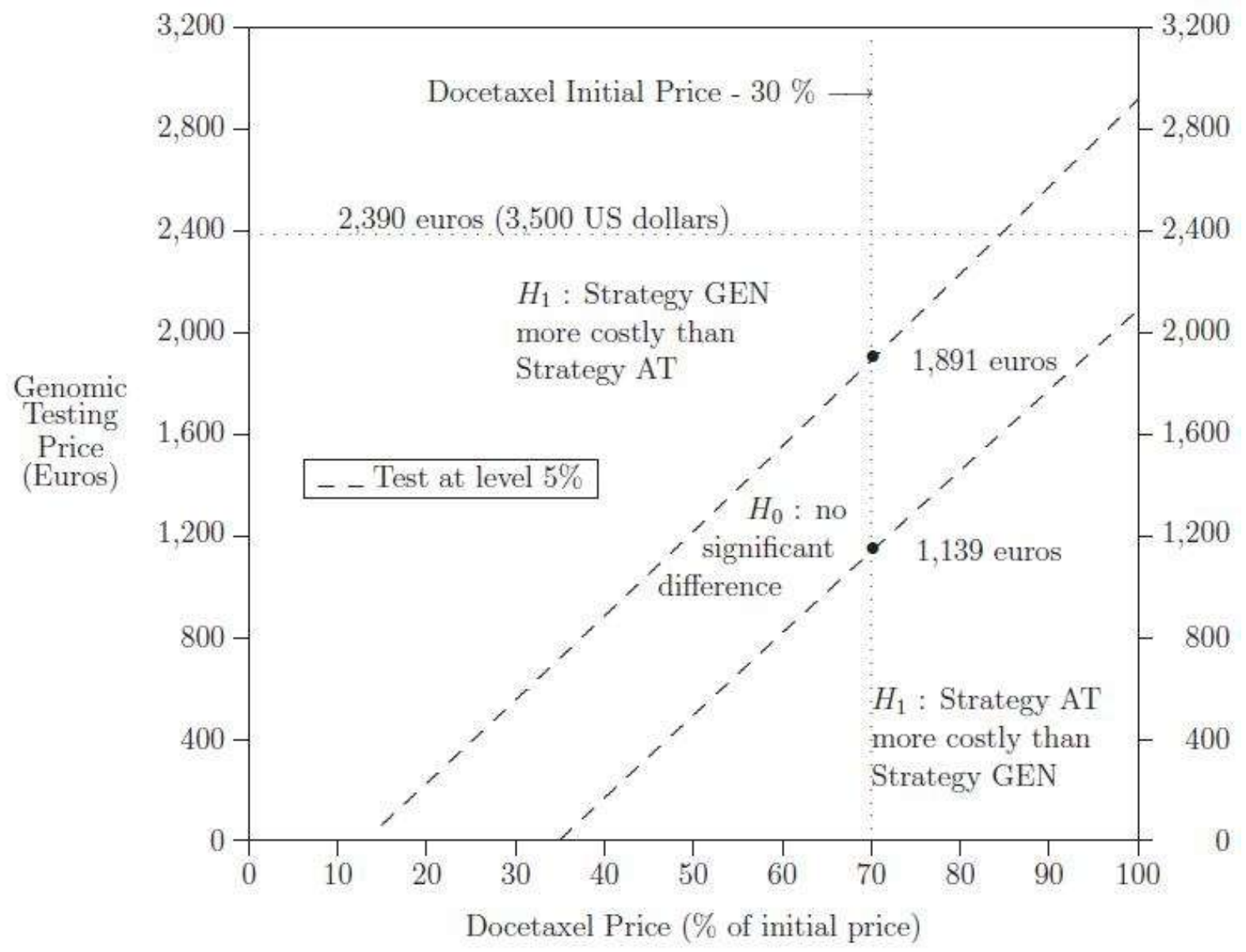

$100 \%$ corresponds to the Docetaxel initial price. For instance, $70 \%$ corresponds to a decrease of $30 \%$ with respect to the Docetaxel initial price.

The hypothesis test was also run for $10 \%$ and for $1 \%$ significance levels. The obtained areas corresponding to the null hypothesis as well as the alternative hypothesis are similar to those of the $5 \%$ test. 


\section{Gopyright Transter Stgtement \\ 空 Springer BREAST CANCER RESEAACH AND TREATMENT}

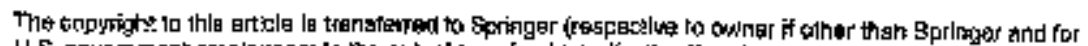
U.S. gowermment amptopens: $\omega$ Q

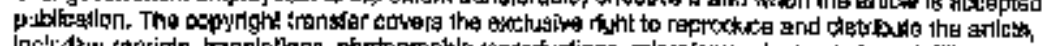

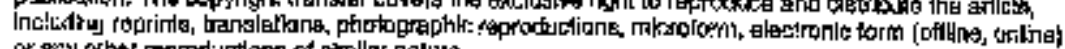
or any enther reprodidetloess of Bamllar nalure.

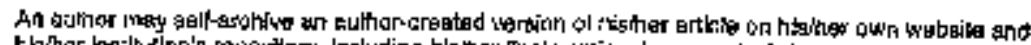

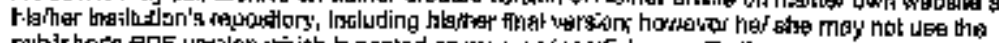

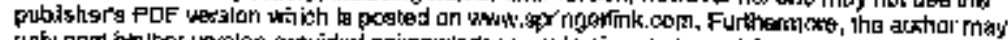

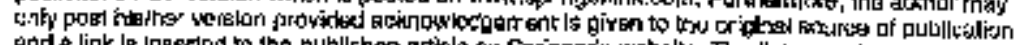

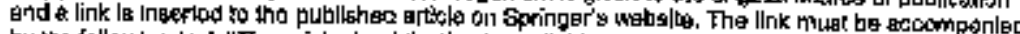

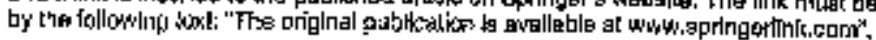

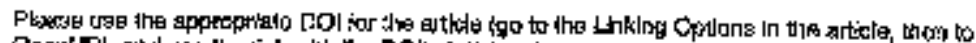

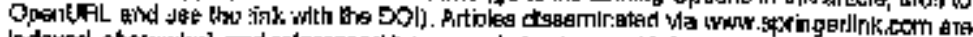

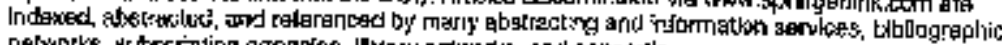

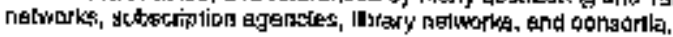

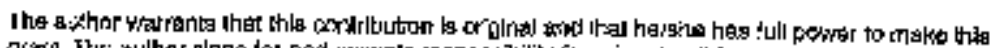

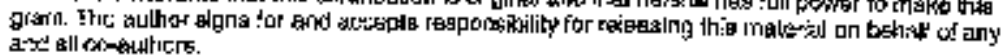

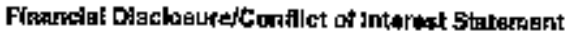

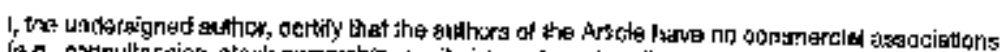

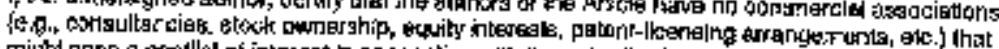

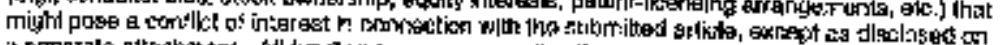

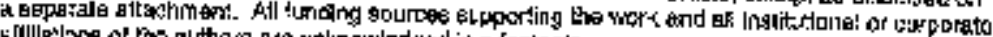

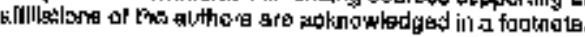

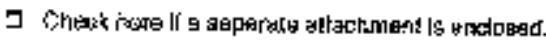

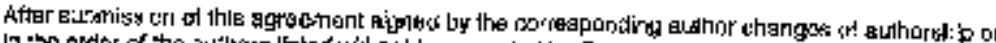
If :

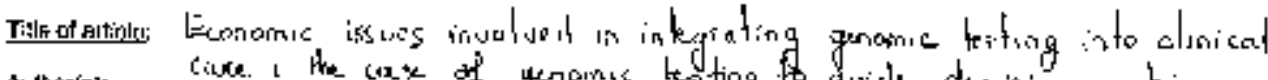

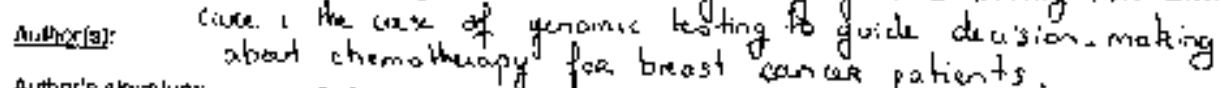

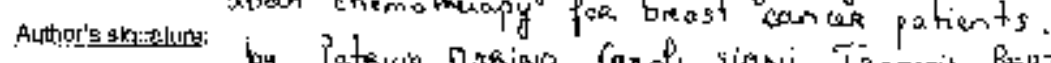

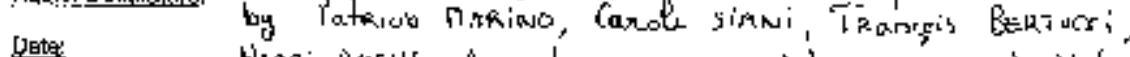

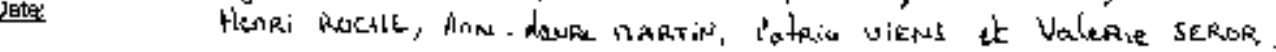

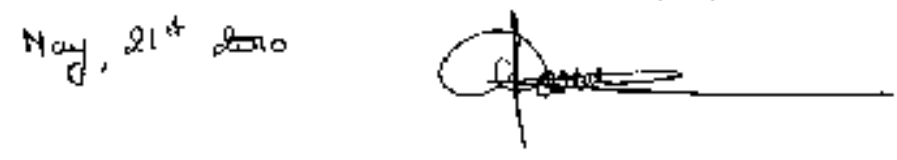

